\title{
Nascidos para comprar: notas sobre o consumismo infantil
}

Resumo: $\bigcirc$ objetivo desse trabalho é analisar os fatores que levam o público infantil a buscar, precocemente, serviços estéticos oferecidos em salões de beleza. Uma pesquisa de campo foi conduzida junto a seis díades de mães com suas respectivas filhas. Como estratégia de pesquisa, uma narrativa ficcional foi conduzida com as crianças; enquanto entrevistas foram usadas com as mães. Como resultado, observou-se que vários estímulos levam as crianças a consumirem serviços estéticos. Entre estes, a referência materna, as influências de familiares, amigos da escola e da mídia, através da televisão, redes sociais e internet. De forma secundária, foi registrado que os serviços mais desejados e consumidos pelo público infantil foram os de manicure e cabelereiro. Em termos de papeis, as mães adquirem o serviço, e dividem com suas filhas o papel de decisão, ao determinarem, juntas, como o consumo acontecerá.

Palavras-chave: Consumo Infantil; Salões de Beleza, Erotização Infantil.

\section{Born to Buy: notes on child consumer}

Abstract: The aim of this paper is to analyze the factors that lead the children to seek early services offered in salons. A qualitative methodology was conducted when six mothers with their daughters were interviewed, last ones using a fictional narrative. Result show that various stimuli lead children to consume aesthetic services, as. maternal reference, family influences, school friends and the high contact with the media through television, social media and internet. It was also found that most desired and consumed services by the children were the manicure and hairdresser and that the main role of mothers in the buying process is the buyer, given that they are sourcing the service, although split with her daughters the role of decision maker to determine together how consumption will happen.

Keywords: Children's Consumption; Beauty salons; Child sexualisation.

\footnotetext{
I Doutora em Engenharia de Produção pela Universidade Federal de Santa Catarina (UFSC), Professora Titular da Universidade Estadual do Ceará (UECE), Membro do Corpo Permanente do Programa de Pós-Graduação em Administração. E-mail: ana.freitas@uece.br

2 Graduada em Administração pela Universidade Estadual do Ceará. E-mail: ly_gia_6@hotmail.com
} 


\section{Introdução}

Na modernidade, como consequência dos avanços tecnológicos nos meios de comunicação em massa, o acesso à informações na mídia se dá de modo extremamente facilitado. Em meio ao turbilhão de estímulos midiáticos, as crianças, que deveriam ser associadas com pureza, ingenuidade e inocência, estão cada vez mais cobertas de mensagens com conteúdos polêmicos, expressando intenções de segunda ordem que, algumas vezes, aparecem camuflados.

Nesta perspectiva de mercado "as empresas vêm brigando para fazer valer seus direitos no grupo antigamente conhecido como crianças" (LINN, 2006, p.21). O público infantil, que antes era, principalmente, alvo de empresas específicas de brinquedos e atividades de entretenimento, hoje é um segmento visado pelo marketing de outros âmbitos profissionais. As crianças são vistas como consumidores, exercem o papel de consumidores (CHAN, 2006), e por isto são uma parcela importante do marketshare das organizações (CARDOSO; ARAÚJO; COQUET, 2005).

A influência das crianças no consumo, e no consequente resultado das organizações, é reconhecida por vários autores (e.g. MACHADO, 2012). Para além desta constatação, o consumismo entre crianças é apresentado como uma macrotendência social, e uma preocupação entre os pesquisadores da área (e.g. BUIJZEN; VALKENBURG, 2003; FLORES et al., 2011). Tal preocupação é ainda mais evidente, à medida que há tempos se reconhece que as experiências absorvidas nas idades iniciais, entre elas aquelas ligados ao comportamento de consumo, repercutem ao longo da vida (WARD; WACKMAN, 1972).

Tais argumentos trazem à tona um assunto de relevância na atualidade, denominado Erotização Infantil. O termo remete a uma infância roubada, na qual a diversidade de estímulos produzidos pela mídia induzem crianças, consideradas seres vulneráveis aos apelos comerciais, a consumirem produtos e/ou serviços não condizentes com sua idade, destruindo, assim, a imagem de ingenuidade que essas possuíam (FIGUEIREDO et al., 2009).

Sobre o assunto Brei, Garcia e Strehlau (2011) analisaram a influência das ações de marketing que se valem de apelos eróticos ou sensuais para estimular a compra, quando o público-alvo são crianças do sexo feminino. $\mathrm{Na}$ ocasião identificaram uma diversidade de estímulos pelo lado da oferta, e as reações produzidas na demanda por parte do segmento-alvo, a partir da identificação do 
desejo por uma variedade de produtos.

A presente pesquisa segue a tradição de pesquisas anteriores, enfocando um contexto específico, os serviços oferecidos em salões de beleza. O objetivo é analisar os fatores que levam o público infantil a buscar, precocemente, serviços estéticos oferecidos em salões de beleza.

\section{Referencial teórico}

A produção de conhecimento sobre a história da infância é relativamente nova. A preocupação com a temática surge de forma mais evidente a partir do século 19 (ARIÉS, 1973). Com o começo tardio, sua definição evoluiu ao longo do tempo e atualmente há certo consenso sobre sua definição como um fenômeno histórico e não simplesmente natural, que se caracteriza por contornos como falta de autonomia, dependência e obediência ao adulto, em troca de proteção (NARODOWSKI, 1993).A concepção de infância como objeto passivo de uma socialização regida por adultos, no entanto, é questionada. O modo como as crianças vêm sendo enxergadas, tratadas e compreendidas vem mudando substancialmente ao longo dos anos. Tal fato se deve a uma quantidade de fatores sociais, culturais e demográficos que têm influenciado a forma como a sociedade, a mídia e até mesmo os próprios pais lidam com a fase infantil.

Em uma perspectiva história, Flores et al.(2011) resgatam que na cultura grega, por exemplo, a disciplina e a educação eram extremamente valorizadas, e, através delas, crianças adquiriam uma formação diversa. Tal fato não era observado na era medieval, na qual estas eram vistas como uma miniaturização dos adultos, dentro de um contexto de poucas preocupações acerca da educação infantil (SANTOS, 2009).Séculos depois, a escola assumiu um importante papel na educação, alfabetização e formação de valores infantis, sendo um local de intensa circulação de informações, conhecimentos e constante aprendizado.

Para compreensão do consumismo infantil, no entanto, é mister reconhecer macrotendências atuais, como a que está contida na crise percebida no modelo familiar tradicional, onde pais separados, movidos pelo sentimento de culpa de ausência acabam cedendo aos pedidos de seus filhos e, para compensar a falta que fazem, compram os objetos de desejo das crianças, contribuindo, assim, para a formação de mais indivíduos consumistas (TRINDADE, 2005).De maneira específica, as mães sempre receberam um papel de destaque nesta discussão, à medida que associaram-se ao 
mito da mãe perfeita; um modelo construído ao longo dos anos que coloca a mulher como capaz de fazer sacrifícios, sem perder a ternura (FORNA, 1998).

Sobre este assunto Richins e Chaplin (2015), em estudo sobre o uso de bens materiais como forma de expressão do amor paternal, mostraram que tal atitude pode potencializar o desenvolvimento do materialismo nos filhos, a longo prazo. Além disto, pesquisas mostram que a mãe que sente culpa adota comportamentos para reparar os danos que acredita ter causado aos filhos, levando a uma relação positiva entre a culpa das mães e a compensação desta culpa pelo consumo (DEDEOĞLU; KAZANÇOĞLU, 2010).

Acrescido a esses fatores, as empresas realizam um verdadeiro bombardeio publicitário para conquistar os novos compradores infantis: além da publicidade tradicional, distribuem brindes, vinculam a imagem de personagens infantis da TV ou cinema aos seus produtos e usam de outros artifícios para induzir as crianças ao consumo exacerbado (STEINBERG; KINCHELOE, 2001). Sobre o assunto, pesquisas anteriores já identificaram uma relação positiva entre o consumo excessivo de televisão, meio massificado de divulgação de propaganda, e o materialismo entre crianças (CHAN, 2003).

O corpo infantil transformou-se em um objeto de constantes investimentos, incluindo entre estes os mais radicais como a necessidade da transformação para atender às exigências de concursos de beleza destinados ao público infantil (MELO; SOARES, 2014). O ideário da beleza aparece em propagandas e o apelo às tecnologias criadas para o embelezamento do corpo é cada vez mais nítido e impactante na formação da identidade infantil feminina. Tornou-se frequente, garotas preocuparem-se com seus corpos e beleza, dedicando boa parte de seu tempo procurando tratamentos estéticos, alisamentos capilares, maquiagens, serviços de manicure, entre outros oferecidos em salões de beleza, o que Borsa (2007) chama de miniadulto superinformatizado ou meninas-mulheres.

Até mesmo em brinquedos infantis, a ideia de cultivo à beleza vem sendo incentivada. As bonecas Barbie, objeto de entretenimento de inúmeras crianças em todo o mundo, em sua maioria possuem cabelos tingidos, olhos claros, rosto bem maquiado, corpo magro, cintura fina e seios fartos, além de constantemente trocarem de roupas, sapatos e acessórios em seus diversos modelos que estão à venda (ROVERI, 2012). Os veículos de comunicação vendem, anunciam e impõem padrões físicos, estéticos e comportamentais a serem imitados, ditando regras às quais as pessoas devem se 
moldar.

Sobre este assunto, Felipe e Guizzo (2003, p.126) explicam que "tais discursos que se repetem produzem efeitos de verdade, de modo a propor qual deve ser o melhor jeito de se comportar, de se vestir, de falar, de exercer a sexualidade". Diante deste contexto, aparecem os órgãos reguladores e Instituições que buscam defender e proteger a integridade infantil. O Instituto Alana no Brasil, organização sem fins lucrativos, fundada em 1994, por exemplo, fiscaliza atividades em prol da defesa dos direitos das crianças e dos adolescentes e suas relações com o consumo em geral e, mais especificamente, com o consumismo exagerado ao qual estão expostos na sociedade contemporânea. Além disto, conforme o Artigo 17 do Estatuto da Criança e do Adolescente preconiza que o direito ao respeito consiste na inviolabilidade da integridade física, psíquica e moral da criança e do adolescente, abrangendo a preservação da imagem, da identidade, da autonomia, dos valores, ideias e crenças, dos espaços e objetos pessoais.

No entanto, apesar da existência de regulamentos e instituições que se dedicam a preservar a integridade infantil, fazendo valer os direitos das crianças, cabe, principalmente, aos pais o dever e a obrigação de prevenir a exposição excessiva de seus filhos a todas essas influências.É o que defende Linn (2006), ao propor que os veículos divulgadores de propagandas voltadas ao público infantil, como os televisores e computadores, sejam retirados do fácil alcance das crianças e o diálogo entre pais e filhos sobre os significados embutidos nas mensagens de marketing sejam conduzidos.

Ainda sobre o tema, Machado (2012, p.4) ratifica que "o papel da família na educação para o consumo das crianças nos dias atuais é muito mais significativo e responsável do que no passado". Quando não se observa essa orientação por parte dos pais, se têm consequências negativas que colaboram para a formação de um consumo desenfreado do público infantil.

$\mathrm{Na}$ verdade, a criança possui grupos de referência, com os quais aprende sobre o ato da compra, como a família, os amigos e as instituições sociais (TRINDADE, 2005). Na família, a criança tem nos pais os seus modelos de postura, estilo de vida e consumo, sendo esses os principais responsáveis pela formação de valores de seus filhos. Cardoso, Araújo e Coquet (2005) ainda lembram que a admiração das crianças por adultos que estão à sua volta faz com elas sintam vontade de comportar-se da mesma maneira. A interação com amigos está diretamente associada à busca por uma aprovação social e a comparação sobre posses é um fenômeno real, que estimula o consumo(- 
CHAN, 2013).Finalmente, as instituições sociais estão representadas pelos meios de comunicação e a mídia, anteriormente comentada.

Com tantos estímulos e referências, o público em questão passa a mudar seu comportamento no consumo e, consequentemente, seu papel de compra. As crianças abandonaram o posto único de usuárias para assumir todos os demais papéis, sendo iniciadoras, influenciadoras, decisoras, compradoras além de consumidoras no ato da compra (CHAN, 2006). Assim, o público infantil, embora seja extremamente influenciado por outros grupos de consumidores, se mostra cada vez mais participativo no processo de compra.

\section{Metodologia da pesquisa}

Para atender os objetivos propostos no presente estudo, optou-se trabalhar com a metodologia qualitativa por meio de uma pesquisa de campo. Foram entrevistadas mães com suas respectivas filhas. A escolha da amostra não probabilística foi feita por conveniência, adotando como critério a condição de serem mães cujas filhas já tivessem consumido algum serviço em salões de beleza. Tal escolha justifica-se pelo fato de que o trabalho buscar identificar quais são os serviços mais procurados pelo público infantil nesse contexto, além de compreender os papéis exercidos pelos pais no processo de compra. Pretendeu-se, também, verificar junto às mães de onde vêm os estímulos que induzem suas filhas a terem o desejo de adquirir esses tipos de serviços.

Como instrumentos para coleta de dados, foram elaborados dois roteiros de entrevista, tendo como foco a díade Mãe- Filha. Na parcela representativa das mães foi aplicado um roteiro semi -estruturado. Já na parcela representativa das filhas utilizou-se a técnica da entrevista ficcional, na qual o entrevistador elabora uma narrativa sobre uma situação hipotética e posteriormente convida o entrevistado a desenvolvê-la, através de respostas aos questionamentos criados.

Foi criado um cenário fictício, que solicitava às crianças que se imaginassem em um "dia de princesa" num salão de beleza, no qual poderiam usufruir de todos os tipos de serviços estéticos oferecidos pelo salão. O narrador fez questão de salientar que as meninas entrevistadas supusessem a autorização e a não-intervenção de suas mães na realização dos serviços. Nesse contexto, foram indagadas sobre como procederiam, caso tivessem essa oportunidade. Foi questionado se gostariam de se parecer com alguém (parentes, amigas, personagens infantis, etc.) e que mudanças estéticas 
concretizariam nelas mesmas, se lhes fossem permitidas. Por fim, interrogou-se às crianças se suas mães concordariam com tais transformações. Para a clara interpretação, tanto a situação hipotética como as perguntas foram elaboradas em linguagem simples e pueril, facilitando o entendimento e a fluida comunicação do narrador com as crianças abordadas.

As entrevistas foram realizadas em 2014 em uma capital do Nordeste. Os entrevistados foram informados sobre o tema da pesquisa e sobre as técnicas para a obtenção de dados utilizada, autorizando que as entrevistas fossem gravadas com finalidade científica depois de reforçada a preservação do sigilo quanto à identidade individual. Posteriormente, os áudios obtidos na coleta de dados foram transcritos e submetidos à análise do pesquisador.

Foram abordadas doze pessoas, seis mães e suas respectivas filhas. Para determinar o número de participantes entrevistadas foi adotado o critério de saturação teórica, haja vista que a relação de informações coletadas começou a se repetir, não surgindo nenhum dado relevante que pudesse ser observado. A idade das mães variou de 28 a 45 anos e as crianças participantes estavam na faixa etária de 5 a 11 anos.

Os procedimentos de análise foram precedidos de um atento escutar dos registros em forma de áudios e de uma detalhada transcrição do conteúdo gravado. Nesta seção, a apresentação dos resultados seguirá a sequencia dos objetivos e será pautada no que foi anteriormente exposto no referencial teórico. O Quadro 1 apresenta o código que será utilizado na exposição dos resultados para identificar os sujeitos da pesquisa.

Quadro I - Identificação das entrevistadas

\begin{tabular}{|c|c|c|c|}
\hline Código & Mãe & Criança & Código \\
\hline M1 & 28 anos & 5 anos & Cl \\
\hline M2 & 30 anos & 10 anos & C2 \\
\hline M3 & 34 anos & 8 anos & C3 \\
\hline M4 & 32 anos & 6 anos & C4 \\
\hline M5 & 35 anos & 9 anos & C5 \\
\hline M6 & 45 anos & 11 anos & C6 \\
\hline
\end{tabular}

\section{Análise de resultados}

Todas as mães entrevistadas afirmaram levar suas filhas em grande parte das vezes que vão 
ao salão de beleza, seja pelo fato de que não têm com quem deixá-las ou porque suas filhas sempre pedem pra ir junto. A frequência com que as mães vão ao salão, acompanhadas de suas filhas, variou de uma vez por mês até mesmo uma vez por semana. Entre os serviços mais consumidos pelas crianças nos salões de beleza estão os de manicure, escovas e penteados, sendo os últimos nem sempre liberados, conforme pode ser apreendido das falas das entrevistadas:

\begin{abstract}
"Ela vai porque ela sempre quer fazer a unha e pede pra fazer o cabelo também. Só que o cabelo eu não deixo porque não tem necessidade de ficar gastando toda vida com cabelo, só quando tem algum aniversário, alguma saída mais assim... Aí a gente vai e faz o cabelo, faz um penteado. Gosta muito de fazer maquiagem também." (MI, 28 anos).

"Ela pede pra fazer a unha decorada, escova no cabelo... que eu tento evitar, né? Mas a unha decorada ela sempre faz." (M3, 34 anos).
\end{abstract}

Além desses serviços apresentados, comuns a todas as filhas, metade das crianças costumava se maquiar com maior frequência em casa, nem sempre fazendo o uso do salão para tal. Foi também identificada, entre as entrevistadas, uma criança que já fazia depilação. As falas a seguir ilustram achados anteriores:

\footnotetext{
"Algumas vezes ela vai, pede pra ir, faz as unhas... Cabelo ainda não. Ainda nunca fiz nada com ela, só uma escova. E a unha, de vez em quando ela faz. [...] Maquiagem ela faz muito, mas só em casa... no salão não." (M5, 35 anos).

"Ela fica pedindo pra fazer a unha. Mas só isso. E nem sempre faz né? Eu só deixo quando tem algum evento, alguma data importante. [...] Ela teve a primeira depilação agora. Teve que fazer a axila." (M2, 30 anos).
}

Segundo as mães, o que mais influencia esse consumo infantil é a referência da mãe como uma figura vaidosa e que exerce papel de espelho para as filhas, fazendo-as imitá-las no modo de se vestir, maquiar, pentear, etc. A importância da referência materna é percebida em falas como:

"Ela diz que quer ficar com o cabelo igual o meu, quando ela crescer. Que ela quer ser loira. Ela diz Mamãe pinta meu cabelo de loiro?" (MI, 28 anos).

"Nós somos espelhos pros filhos sempre né? Uma mãe vaidosa gera uma filha vaidosa naturalmente, sem você ficar exigindo isso. A criança se espelha em você, então se você tá de unha pronta ela também quer estar né?" (M4, 32 anos)

"Eu gosto do jeito que ela se veste, que ela se maquia e tudo. Quando eu crescer, queria ser assim." (C3, 8 anos)

Entretanto, a maioria das mães apontou a mídia como um grande bombardeador de ideias que leva as crianças a fazerem pedidos incessantes dos mais diversos gêneros. Esse argumento já foi anteriormente explicado por autores como Chan (2003) e Trindade (2005) segundo o qual o ato da compra é aprendido pelas crianças por meio de três grupos de referência: a família, os amigos e as 
instituições sociais (como os meios de comunicação e a propaganda). Tais grupos são citados nos discursos a seguir:

"Ela vê e pede. Ou então diz "mamãe olha aqui a propaganda na televisão". Aí manda eu olhar pra mim ver o que é que ela quer." (MI, 28 anos)

"Tem, no meu balé. Minha amiga favorita lá no balé é a Maria Clara, que eu fui pro aniversário uma vez com minha mãe. Eu queria ser que nem ela." (Cl, 5 anos)

"Minha cunhada é esteticista né. Aí minha cunhada tava chamando ela pra fazer uma limpeza no rosto, porque nessa idade já começa a aparecer algumas acnes né. Aí ontem ela falou que poderia fazer com a minha cunhada que é esteticista que ficou comentando pra ela [...]Essa minha cunhada ela gosta. Ela fala do cabelo vermelho da minha cunhada. Então ela sempre diz que quando for pintar o cabelo vai pintar de vermelho. Ela tem um cuidado muito grande com pele, cabelo..." (M2, 30 anos)

Ainda no que tange aos estímulos que despertam na criança o desejo de consumir serviços de beleza, os amigos da escola foram lembrados por um terço das mães entrevistadas como sendo muito importantes na formação ideológica de suas filhas, corroborando com pesquisas anteriores (e.g. CHAN, 2013). Tal fato é exposto na fala abaixo:

"Pra mim é muito complicado né, porque como eu disse o convívio que ela tem com outras crianças é somente o convívio que ela tem na escola. Então em casa todos nós somos adultos e em casa não tem com quem ela brincar, não tem com quem ela viver esse mundo infantil [...] Eu vejo as crianças da fase dela no colégio, as amigas dela já tão tudo namorando, tudo com paquerinha já, as conversas são bem diferentes das conversas que ela tem..." (M6, 45 anos).

A mídia foi citada por todas as mães entrevistadas como sendo um incentivador ao consumo de suas filhas. Metade destacou as propagandas e programas de televisão e a outra metade mencionou a influência da internet nos apelos repetitivos das crianças. As mães atribuíram à mídia o papel de culpada por boa parte do consumismo de suas meninas, corroborando com pesquisas anteriores sobre o assunto (STEINBERG; KINCHELOE, 2001). Isso é percebido em falas como:

"Ah, primeiro ela diz " ah, eu vi... Isso aqui faz assim, assado." Ou então "isso aqui é aquele negócio que eu tinha falado que apareceu na televisão". Fica primeiro assim só especulando... dizendo as qualidades. Aí depois é que ela diz" pode comprar?"” (M2, 30 anos).

"É que ela vê muito esses vídeos que tem na internet de crianças postando atualmente né? São até tem um nomezinho que chama.. tutorial! Aí ela fica assistindo, então ela vê aquilo dali e estimula mais ainda. Ela já gosta, mas isso aí estimula muito. Acho que realmente é a mídia, a internet que faz com que ela fique mais assim." (M3, 34 anos)

"A mídia tá aí pra fazer exercer esse papel né, de capitalismo, de consumismo e a criança que tem acesso a uma televisão ou a um computador sempre vai ver produtos interessantes infantis e vai pedir pro pai e pra mãe. Ela faz isso com frequência, [...]." (M4,32 anos).

"Ela segue uma menina da idade dela no Instagram. Uma mini blogueira. Aí ela fica mostrando as coisas que compra: maquiagens, bonecas e essas coisas todas. Aí ela me pede pra ir nas lojas comprar maquiagem, sombra, esse tipo de coisa [...]A mídia. Ela é bem influenciada pela mídia. É tanto que agora eu só deixo ela assistir TV duas vezes na semana porque ela tava muito influenciada pela mídia, quer fazer tudo que ela assiste, então eu tô até monitorando isso aí porque já tá demais." (M5, 35 anos). 
Quando questionadas quanto à forma com que lidam com os apelos de suas filhas, metade das mães declarou fazer o possível para dar o que as crianças pedem, sob a justificativa de que passam muito tempo fora e tentam compensar essa ausência fazendo aquilo que as pequenas gostam. O sentimento de culpa, já identificado em trabalhos anteriores (LIMA; BOTELHO, 2009; DEDEOĞLU; KAZANÇOĞLU, 2010), pode ser ilustrado no depoimento a seguir:

"Hoje em dia a vida da gente é muito conturbada. Então não só eu como a maioria das mães que eu convivo, e eu convivo com muita mãe pelo fato de ser professora, a gente acaba cedendo muito aos apelos dos filhos até por conta da ausência da gente. Isso na psicologia é totalmente explicado né. Então a gente acaba cedendo muito e às vezes até pela ausência da gente, a gente tenta até compensar em forma dos pedidos dela." (M6, 45 anos)

Entretanto, a outra metade das mães abordadas asseverou que não costuma ceder aos pedidos, fazendo questão de explicar às filhas que nem sempre podem atender aos seus desejos, respeitando as condições financeiras da família e a faixa etária das crianças, que, muitas vezes, não permitem a efetuação dos serviços.

"Eu lido com muita naturalidade. Do mesmo jeito que a minha mãe lidava comigo. Nunca me deu tudo, sempre disse o que era certo.. E assim eu faço com eles. A gente dá o que a gente pode dar e quando a gente quer dar. E eles sabem e entendem... Às vezes, por serem crianças, querem, cobram e podem até chorar mas eu não me deixo ceder. Eles até brincam que eu sou a rainha do "não"." (M4, 32 anos)

"Não... nem sempre eu cedo né? Eu tento frear um pouquinho. É interessante isso da mulher, a questão da vaidade, a questão de ir pra um salão de beleza... o fato de ela ser minha companheira e ficar me acompanhando aos salões... Mas eu freio um pouquinho porque tem coisas que não é ainda pra idade dela né? Ela gosta muito de maquiagem, de se maquiar. Então eu digo “ Bia, não é assim, a sua pele não pode ficar usando esse tipo de maquiagem, as suas unhas também não pode ficar pintando com frequência com esses esmaltes aí eu sempre tento conversar com ela e mostrar que nem tudo vai fazer bem a ela." (M3, 34 anos)

Com relação aos papeis adotados pelos pais no processo de compra, foi constatado que as mães assumem o papel de compradoras (já que são elas que exercem o consumo, mesmo não sendo utilitárias do serviço) e dividem com as filhas o papel de decisor, haja vista que juntas determinam como, quanto e onde consumir. Abaixo estão transcritas algumas respostas das crianças quando questionadas quanto à permissão e concordância da mãe acerca dos serviços estéticos:

“Mais ou menos... porque às vezes ela não deixa. É mais assim quando tem festa." (C2, 10 anos).

"O cabelo não, mas a unha sim. Porque ela já acha meu cabelo muito bonito e eu não. E ela diz também que sou muito nova." (C5, 9 anos).

"Acho, porque é o que eu faço normalmente. Só que é um de cada vez, eu não faço tudo num dia. Às vezes eu faço escova... Quando tem uma festa ela deixa fazer tudo isso, mas é bem difícil ter uma festa." (C6, II anos).

Ao final do roteiro questionava-se sobre o que as mães faziam para proteger suas filhas da 
exposição excessiva de fatores que contribuem para a "miniaturização de adultos", pois, como Linn (2006) mencionou, os pais é que são os responsáveis por prevenir os efeitos negativos que o marketing e a mídia causam nas crianças. Dois terços das mães afirmaram que o diálogo é a maneira mais adequada de evitar esse comportamento precoce. Outras declararam incentivar a filha a ter contato com jogos, programas, brinquedos e roupas infantis de modo a prorrogar o período pueril o máximo possível. As atitudes das mães são descritas a seguir:

"[..] a gente incentiva muito assim brinquedos, jogos... Ela tem bastante e sempre que ela pede e eu posso comprar eu tô tentando comprar porque eu quero que ela viva a infância dela o máximo possível. Então a gente sempre vê por esse lado. As coisas que ela assiste na TV tem muita coisa ainda de criança[...]" (M6, 45 anos)

"[...] Na grande parte do tempo a gente procura fazer com que ela vivencie o tempo dela... Conversando, a gente conversa muito. Mostrando... às vezes ela pede pra comprar uma sandália de salto e eu não deixo, porque ela ainda é criança e quando eu vejo uma criança com salto eu digo" Tá vendo, Lara como é feio?". Então eu mostro pra ela e a gente conversa muito... é muito na base da conversa e do diálogo." (M5,35 anos)

"[...] Mas eles são crianças, eles dormem no horário de criança, eles acordam, fazem tudo que criança tem que fazer. Quando eu vou comprar roupa pra eles, compro roupa pra idade deles, nada de decote, de roupas de "mulherzinha". Isso nem existe, isso não é nem conversado.[...] Então é muito através do diálogo e da conversa. Nós temos que ensinar nossos filhos como eles devem ser e exemplo. O exemplo é tudo." (M4, 32 anos)

"Bom, eu tento prevenir o máximo que eu posso. Ela veio começar a assistir alguns seriados há pouco tempo. Ela ainda gosta muito de desenho, ela não assiste novela. Eu não concordo, entendeu? Eu tento fazer de tudo pra que ela aproveite a época dela. Assim, vai chegar o momento certo dela ter esse tipo de atitudes, mas agora não é a hora né? E eu tento fazer de tudo, mostrando, conversando, assistindo desenhos com ela... Comprando com ela vestidos coloridos. Sabe assim? Então a minha forma é essa: ficar ao lado dela. Mostrando" olha minha filha, como é feio fulana de tal assim assado... Tão bom ser assim, tão bom poder fazer coisas de criança ainda..." E aí ela vai curtindo ainda." (M2, 30 anos)

\section{Considerações finais}

A questão de partida que deu origem a esse trabalho acarretou uma série de entrevistas na tentativa de descobrir o que influencia crianças a terem o desejo de consumir serviços em salões de beleza. Após a pesquisa de campo, foram identificados que os serviços mais procurados pelas crianças nos salões de beleza são os de manicure e cabeleireiros, os quais realizam escovas e penteados. Algumas crianças manifestaram o desejo de fazer maquiagens, algo que nem sempre as mães permitiam, seja dentro ou fora dos estúdios de beleza.

Foram constatados os vários estímulos que criam nas crianças o desejo de consumir serviços em salões de beleza. A figura materna, como referência feminina, foi apontada tanto pelas mães 
como pelas crianças como sendo um fator de grande importância no modo de consumir das filhas. Além disto, outros entes da família e amigos da escola também servem de referência para os apelos infantis. Ademais, a mídia e suas instituições sociais, tais como a televisão e a internet, foram bastante citadas pelas mães e criticadas por influenciarem suas filhas a estarem constantemente solicitando produtos e serviços dos quais tomam conhecimento.

Ainda neste contexto, embora a culpa tenha aparecido como um sentimento vinculado a busca por restabelecer uma relação prejudicada pela ausência física, boa parte das mães entende a necessidade de restringir o acesso das crianças ao consumo estético. Como estratégias, as mães buscam diminuir o tempo de exposição às mídias, com destaque especial às mídias sociais e internet, e oferecem às crianças artefatos apropriados para sua idade. $O$ primeiro movimento busca diminuir o apelo midiático, mas há uma esfera que é aquela que ocorre dentro das escolas, no contato e na comparação com os amigos, que nem sempre é possível controlar.

Finalmente, foi constatado que o papel dos pais, no caso das mães, no processo de compra de suas filhas foi o de comprador, já que são elas que de fato realizam a compra, pagando pelo produto ou serviço. Viu-se também que o papel de decisor é compartilhado entre mãe e filha, pois juntas indicam como a compra será feita e qual serviço será escolhido. Dessa forma, os achados da pesquisa são de grande relevância e utilidade para os gerentes atuantes no setor de salões de beleza, os quais poderão se apoderar dessas informações para lidar de forma correta com os públicos-alvo desses serviços estéticos. À vista do que foi exposto, os resultados podem ajudar a subsidiar políticas públicas que tratem sobre a publicidade e do consumismo, no contexto infantil.

\section{Referências}

ARIÉS, Philippe. História social da criança e da família. 2º ed. Rio de Janeiro: Guanabara, 1973. $279 \mathrm{p}$.

BORSA, J. Sobre nossas crianças. Zero Hora, 12/10/2007.

BREI, Vinícius Andrade; GARCIA, Luciana Burnett; STREHLAU, Suzane. A Influência do Marketing na Erotização Precoce Infantil Feminina. Teoria e Prática em Administração, v. 1, n. 1, p. 97-116, 2011.

BUIJZEN, MONIEK; VALKENBURG, PATTI M.The Unintended Effects of Television Advertising.Communication Research, V. 30 N. 5, p. 483-503, 2003.

CARDOSO, A.; ARAÚJO, M.; COQUET, E. Importância e significado que as crianças atri- 
buem ao vestuário, às marcas e à moda - recurso à representação gráfica. XXVIII Congresso Brasileiro de Ciências da Comunicação. Rio de Janeiro: INTERCOM, 2005.

CHAN, K. Materialism among Chinese children in Hong Kong.Young Consumers, v. 4, n.4, p. 47-61, 2003.

CHAN, K. Exploring children's perceptions of material possessions: A drawing study. Qualitative Market Research, v. 9, 2006.

CHAN, K. Development of materialistic values among children and adolescents.Young Consumers, v. 14, n.3, p. 244-257, 2013.

DEDEOĞLU, A.; KAZANÇOĞLU, İ. The feelings of consumer guilt: A phenomenological exploration. Journalof Business Economicsand Management, v. 11, n.3, p. 462-482, 2010.

ECA - Estatuto da Criança e do Adolescente - Lei no 8.069 de 13 de Julho de 1990. Art. 17. Disponível em: http://www.jusbrasil.com.br/topicos/10618111/artigo-17-da-lei-n-8069-de-13-de-julho-de-1990. Acesso em: 26 de maio, 2014.

FELIPE, Jane; GUIZZO, Bianca Salazar. Erotização dos corpos infantis na sociedade de consumo. Proposiçóes, v.14, n.3, p.119-130, set/dez, 2003.

FIGUREIDO, A.O. G.et al.A influência televisiva como desencadeadora da erotização infantil na contemporaneidade (3 - 5 anos). Pedagogia em ação, v.1, n.2, p. 63-70, 2009.

FLORES, A.L.P.; OLIVEIRA JÚNIOR, J.N.; SANTOS, M.E.V.; TEIXEIRA, S.S. Erotização e Infância: as duas faces da publicidade. Revista Anagrama. São Paulo: 2011.

FORNA, A. Mother of all myths: How society moulds and constrains mothers. HarperCollins, 1998.

GIL, Antonio Carlos. Como elaborar projetos de pesquisa. Sáo Paulo. Editora Atlas. 2002.

KOTLER, Philip; KELLER, Kevin.Administração de Marketing.12o ed.São Paulo: Pearson, 2006.

LINN, Susan. Crianças do Consumo: a infância roubada. São Paulo: Instituto Alana, 2006.

MACHADO, Alexandre. A sociedade do consumo infantil. São Paulo, 2012.

MELO, R. S.; SOARES, R. F. R. Infâncias Glitz: um estudo sobre as imposiçóes dos concursos de beleza aos corpos infantis. Zero-a-seis, v. 16, n. 30 p. 245-258, Florianópolis, jul-dez 2014.

NARODOWSKI, M. Infância e poder: a confrontação da pedagogia moderna. Tese (Doutorado em Educação) - Universidade Estadual de Campinas, 1993.

RICHINS, M. L. ; CHAPLIN, L. N. Parenting Foster Materialism in the Next Generation. JournalofConsumerResearch, v.41, n.6, p. 1333-1357, 2015.

ROVERI, F. T. Barbie na educação de meninas: do rosa ao choque. São Paulo: Annablume, 2012.

SANTOS, Ivone. A cultura do consumo e a erotização na infância. Trabalho de Conclusão de Curso. ECA- USP, 2009.

STEINBERG, S.R.; KINCHELOE, J. L. (orgs). Cultura Infantil: A construção corporativa da Infância. Rio de Janeiro: Civilização Brasileira, 2001. 
SUZANA, Lima; BOTELHO, Delane. Culpa das Mães para com seus Filhos e sua Relação com Decisões de Consumo. XXXVIII Encontro da ANPAD. Rio de Janeiro, 2014.

TRINDADE, Christiane. A interferência de alteraçóes sociais sobre o comportamento do consumidor infantil. FEAC- USP. São Paulo, 2005.

WARD, S.; WACKMAN, D. B. Children's Purchase Influence Attempts and Parental Yielding. Journal of Marketing Research, v. 9, p. 316-319, 1972. 